ORIGINAL RESEARCH

\title{
Physiological Responses of Ultraendurance Athletes and Nonathletes During an Attempt to Summit Denali
}

\author{
Erik Leon Olav Seedhouse, PhD; Andrew Philip Blaber, PhD \\ From the Aerospace Physiology Laboratory, School of Kinesiology, Simon Fraser University, Burnaby, British Columbia, Canada
}

\begin{abstract}
Objective.-To compare altitude responses of 2 ultraendurance athletes and 2 nonathletes during a 2-week expedition on Denali (Mount McKinley).

Methods. - The severity of acute mountain sickness (AMS) symptoms (Lake Louise AMS guidelines) and pulmonary function parameters (forced vital capacity, forced expiratory volume in 1 second, peak expiratory flow) as well as resting heart rate and arterial oxygen saturation measurements were taken during the climb. Baseline measurements were made at $375 \mathrm{~m}$, and field tests were performed at altitudes of $2200 \mathrm{~m}, 2400 \mathrm{~m}, 3000 \mathrm{~m}, 3400 \mathrm{~m}, 4100 \mathrm{~m}, 4300 \mathrm{~m}$, and $10 \mathrm{~m}$.

Results.-Nonathletes reported moderate AMS symptoms at altitudes up to and including $3000 \mathrm{~m}$, whereas ultraendurance athletes reported moderate AMS symptoms at altitudes above $3000 \mathrm{~m}$. Considerable daily variation existed in pulmonary function measures within and between groups; however, the largest shift from baseline and between groups occurred at $3000 \mathrm{~m}$ where ultraendurance athletes had increased and nonathletes had decreased peak expiratory flow and forced vital capacity. Resting heart rate increased and arterial oxygen saturation decreased with altitude.

Conclusions.- Highly aerobically fit individuals may be more susceptible to delayed and more prolonged onset of AMS than are moderately fit individuals. Pulmonary function, although highly variable, also may be dissimilar between these groups.
\end{abstract}

Key words: acute mountain sickness, cardiovascular, hypoxia, oxygen saturation, pulmonary function

\section{Introduction}

High-altitude mountaineering is becoming increasingly popular. Numerous studies have investigated the physiological changes that take place under the conditions of hypoxia. ${ }^{1,2}$ A review of 4 decades of research into the effects of altitude on maximal and submaximal exercise performance revealed a large qualitative contribution of prealtitude fitness level and a minimal contribution of gender. ${ }^{3}$ However, few reports have been made on altitude's effect upon ultraendurance athletes during a climbing expedition. Extreme environmental situations are useful tools for investigating the processes of physiological adaptation. In an attempt to study the combined effect of hypoxia, environment, and physical stress, this paper takes advantage of an unusual opportunity to study cardiorespiratory challenges in ultraendurance athletes.

Acute exposure to altitude results in a decrease in the

Corresponding author: Andrew P. Blaber, PhD, Aerospace Physiology Laboratory, School of Kinesiology, Simon Fraser University, 8888 University Dr, Burnaby, BC V5A 1S6, Canada (e-mail: ablaber@sfu. ca). amount of oxygen available to perform physical work and a reduction in maximal aerobic power above 580 m. ${ }^{3-5}$ Chronic exposure to this hypoxic stress stimulates acclimatization, which includes several physiological adaptations that markedly improve the ability to perform submaximal work at altitude. ${ }^{1}$ Increases in hemoglobin and hematocrit improve the oxygen-carrying capacity of the blood. ${ }^{4}$ With prolonged exposure comes a decline in aerobic capacity, which is more pronounced in aerobically fit individuals. This decline has been found to be the result of a reduction in muscle mass and oxidative capacity without a loss of capillarity. ${ }^{6}$

Exposure to high altitude can also lead to acute mountain sickness (AMS), symptoms of which are commonly experienced above $2500 \mathrm{~m} .^{2}$ Acute mountain sickness is characterized by symptoms such as headache, dizziness, nausea, fatigue, and irritability. ${ }^{1}$ Symptom occurrence and severity can be assessed by the Lake Louise scoring system. ${ }^{7}$ The severity, rapidity of onset, and duration of AMS symptoms vary individually and are related to both level of altitude and rate of ascent. ${ }^{1,2}$ 
Table 1. Subject baseline characteristics*

\begin{tabular}{|c|c|c|c|c|c|c|c|c|c|c|}
\hline $\begin{array}{l}\text { Subject/ } \\
\text { category }\end{array}$ & Gender & $\begin{array}{c}\text { Age } \\
(y)\end{array}$ & $\begin{array}{l}\text { Height } \\
(m)\end{array}$ & $\begin{array}{c}\text { Weight } \\
\quad(k g)\end{array}$ & $\begin{array}{c}\text { AMS } \\
\text { score }\end{array}$ & $\begin{array}{c}\text { Measured/ } \\
\text { predicted } \neq \\
F V C(L)\end{array}$ & $\begin{array}{l}\text { Measured/ } \\
\text { predicted } \neq \\
F E V_{1.0}(L)\end{array}$ & $\begin{array}{c}\text { Measured/ } \\
\text { predicted } \ddagger \\
F E V_{1.0} / F V C\end{array}$ & $\begin{array}{l}\text { Measured/ } \\
\text { predicted } \$ \\
\operatorname{PEF}\left(L \cdot S^{-1}\right)\end{array}$ & $\begin{array}{c}\dot{V} \mathrm{O}_{2} \max \\
\left(\mathrm{mL} \cdot \mathrm{min}^{-1}\right. \\
\left.\cdot \mathrm{kg}^{-1}\right)\end{array}$ \\
\hline $1 / \mathrm{UA}$ & M & 35 & 1.72 & 62 & 0 & $4.40 / 5.01$ & $3.40 / 4.06$ & $80.3 / 83.2$ & $9.41 / 9.74$ & 72.2 \\
\hline 2/UA & $\mathrm{F}$ & 39 & 1.67 & 53 & 0 & $3.34 / 3.92$ & $3.04 / 3.20$ & $91.0 / 82.5$ & $8.21 / 7.24$ & 71.6 \\
\hline 3/NA & M & 27 & 1.79 & 75 & 0 & $5.40 / 5.60$ & $4.40 / 4.59$ & $81.5 / 84.3$ & $11.0 / 10.3$ & 52.8 \\
\hline 4/NA & $\mathrm{F}$ & 27 & 1.62 & 68 & 0 & $4.36 / 3.76$ & $3.84 / 3.21$ & $88.1 / 85.1$ & $7.78 / 6.93$ & 48.0 \\
\hline
\end{tabular}

*AMS indicates acute mountain sickness; FVC, forced vital capacity; $\mathrm{FEV}_{1.0}$, forced expiratory volume in 1 second; PEF, peak expiratory flow; $\dot{\mathrm{VO}}_{2} \mathrm{max}$, maximal oxygen uptake; UA, ultraendurance athlete; NA, nonathlete.

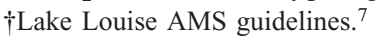

$\$$ Predicted values calculated based on Hankinson et al. ${ }^{8}$

This paper examines the cardiorespiratory characteristics and AMS symptoms of 2 ultraendurance athletes and 2 nonathletes during a 2-week expedition to Denali (Mount McKinley), located at latitude $63^{\circ} \mathrm{N}$, Alaska, United States. Denali is located a few hundred kilometers south of the Arctic Circle and is the highest peak (6194 m, 20320 feet) in North America. Individuals attempting to climb it must contend with temperatures that range from $35^{\circ} \mathrm{C}$ in the daytime to $-45^{\circ} \mathrm{C}$ at night. Avalanches, crevasses, and possibility of blizzards pose a constant danger.

\section{Methods}

\section{SUBJECTS}

The climbing team consisted of 2 men and 2 women (Table 1). The Ethics Review Committee of Simon Fraser University approved the study protocol, and each subject signed an informed consent statement before participation and could withdraw without prejudice at any time. Subjects had no history of major medical illness and were not on medications within 1 month of the expedition. They were lowland natives and permanent lowland residents $(<500 \mathrm{~m}$ above sea level $)$ and had not been exposed to altitudes above $1000 \mathrm{~m}$ within 6 months before the start of this study. The athletes were ultraendurance athletes, each with more than 15 years' experience of competing at world-class level with top 3 finishes in international adventure running and ultramarathon competitions. Both had previous alpine experience of more than 5 years. The nonathletes were medical doctors and experienced climbers, each with more than 6 years' alpine-type climbing experience. No subject had shown symptoms of AMS during previous climbs. Subjects were requested to refrain from taking any antioxidant preparations and prophylactic medication against AMS for the duration of the study.

\section{PHYSIOLOGICAL MEASUREMENTS}

Presence and severity of AMS symptoms were assessed by the Lake Louise criteria. ${ }^{7}$ Pulmonary measures were collected with an automated Jaeger SpiroPro pulmonary function unit (Jaeger Toennies GmbH, Hoechberg, Germany). This device complies with American Thoracic Society guidelines and was calibrated for flow and volume with a precision 3-L flow-volume syringe for baseline measurements and just before departure. Predicted values for each subject were calculated by reference equations for the US Caucasian general population. ${ }^{8} \mathrm{Be}-$ cause of weight and packing constraints related to climbers carrying all their provisions and experimental equipment up and down the mountain, the syringe was not taken on the expedition. Because there was a possibility of the device being altered during the climb, the pulmonary function unit was tested with the same calibration syringe in the Aerospace Physiology Laboratory at Simon Fraser University upon return. The parameters recorded were forced vital capacity (FVC), forced expiratory volume in 1 second $\left(\mathrm{FEV}_{1.0}\right)$, and peak expiratory flow (PEF). The best of 3 measurements was recorded for analysis. Heart rate (HR) was determined by palpation, and arterial oxygen saturation $\left(\mathrm{SaO}_{2}\right)$ was measured with a portable monitor (ApnoeScreen Pro, Jaeger Toennies GmbH).

\section{BASELINE DATA COLLECTION}

All baseline measures were conducted in the Aerospace Physiology Laboratory (altitude $375 \mathrm{~m}$ ). Seven days before departure, each subject completed a maximal oxygen uptake test $\left(\dot{\mathrm{V}}_{2} \max \right)$ measured directly on an electronically braked cycle ergometer (EOS Ergosprint, Jaeger, Germany) with a ramped power protocol. Breathby-breath measures of ventilatory variables (volume turbine: VMM-110, Alpha Technologies, Laguna Beach, 
CA; respiratory gas mass spectrometer: RAMS, Marquette Electronics, Milwaukee, WI) were determined with a real-time computer-based system (First Breath Inc, St Agatha, ON, Canada). Pulmonary function tests were performed and $\mathrm{HR}$ and $\mathrm{SaO}_{2}$ measurements were obtained between 10:00 AM and noon 5 days before departure. For 3 consecutive days before departure, between 10:00 AM and noon, subjects completed baseline AMS scores. Acute mountain sickness questionnaires were conducted at least 1 hour after eating or performing any exercise.

\section{ALTITUDE DATA COLLECTION}

Resting $\mathrm{HR}$, pulmonary function, and $\mathrm{SaO}_{2}$ measures were performed between 9:00 AM and 10:00 AM under control of one of the physicians or the expedition leader. Subjects interviewed each other daily for AMS between 10:00 AM and 11:00 AM at least 1 hour after they had eaten or performed any physical exercise and before that day's climb.

\section{EXPEDITION PROFILE AND ENVIRONMENTAL CONDITIONS}

The team planned for a 20-day expedition given the highly variable weather conditions on the mountain. An optimal summit time was anticipated at 10 to 12 days. The itinerary included a flight from Vancouver (altitude $12 \mathrm{~m}$ ) to Anchorage (altitude $10 \mathrm{~m}$ ) and overland travel to Talkeetna (altitude $100 \mathrm{~m}$ ), $200 \mathrm{~km}$ north of Anchorage. Day 1 for the expedition was considered to start the next day when they departed Talkeetna on a flight to Kahiltna Base Camp (altitude $2200 \mathrm{~m}$ ) and the ascent of Denali began. During the climbing season, the climbers could expect almost 24 hours of daylight for the duration of the climb.

\section{ANALYSES}

Data were investigated from baseline $(375 \mathrm{~m})$, climbing (2200 m, $2400 \mathrm{~m}, 3000 \mathrm{~m}, 3400 \mathrm{~m}, 4100 \mathrm{~m}, 4300 \mathrm{~m})$ and postclimb $(10 \mathrm{~m})$.

\section{Results}

The ascent profile of the team is presented in Figure 1. The largest single increase in altitude occurred on day 1 with the flight from Talkeetna to the Kahiltna Base Camp. Each subject carried about $50 \mathrm{~kg}$ of equipment divided between sled and backpack. Ascents were done as single carry; however, because of the steep and treacherous terrain from $3500 \mathrm{~m}$ to $4300 \mathrm{~m}$, the team
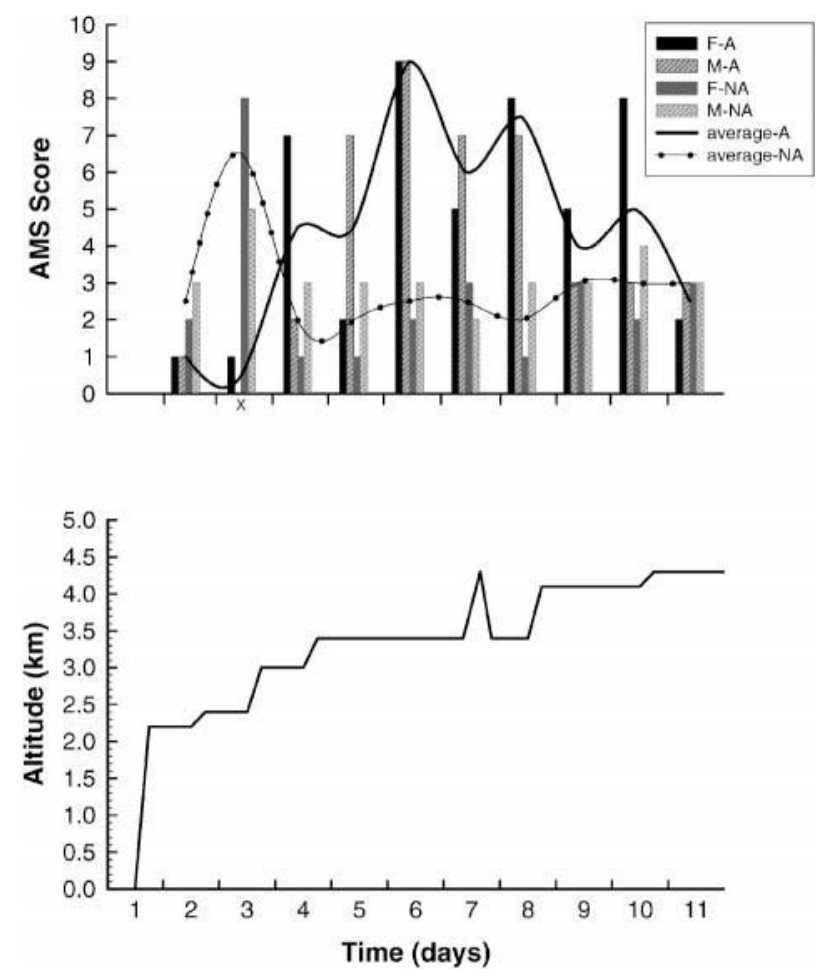

Figure 1. Top: Individual (vertical bars) acute mountain sickness scores ${ }^{7}$ with average ultraendurance athlete (average A) and average nonathlete (average NA) values (lines) reported from days 1 to 11 during the climb. Bottom: Ascent profile from days 1 to 11 of the climb.

decided to do a double carry to $4300 \mathrm{~m}$ on day 7 . The loads were divided in half and the team proceeded from $3500 \mathrm{~m}$ to Basin Camp at $4300 \mathrm{~m}$ over a 4-hour period. At $4300 \mathrm{~m}$ the gear was cached and the team then descended to $3500 \mathrm{~m}$ where they spent the night. On day 8 the team loaded up with the remainder of their supplies and proceeded to $4100 \mathrm{~m}$ where they spent 2 days to rest and acclimatize. On day 10 the team proceeded to Basin Camp (4300 m) where they waited for appropriate weather conditions for a summit attempt. Because of equipment problems and frostbite during their summit attempt on day 12, the team left for home.

The lowest nighttime temperature during the climb was $-42^{\circ} \mathrm{C}$, recorded at $4100 \mathrm{~m}$ on day 9; however, nighttime temperatures were typically on the order of $-10^{\circ} \mathrm{C}$. Ambient temperatures during the day rose from $-5^{\circ} \mathrm{C}$ at $10: 00 \mathrm{AM}$ to $34^{\circ} \mathrm{C}$ at 4:00 $\mathrm{PM}$. Meteorological conditions consisted mostly of blue skies and sunshine for the duration of the climb, with the exception of days 6 and 9 when the climbers were exposed to storms for periods of more than 2 hours. During this period, temperatures dropped to $-15^{\circ} \mathrm{C}$ with winds of $80 \mathrm{~km} \cdot \mathrm{h}^{-1}$.

Results from the Lake Louise self-report questionnaire 
Table 2. Respiratory changes with altitude*

\begin{tabular}{|c|c|c|c|c|c|c|}
\hline & $\begin{array}{c}2200 \mathrm{~m} \\
\text { day } 1\end{array}$ & $\begin{array}{c}2400 \mathrm{~m} \\
\text { day } 3\end{array}$ & $\begin{array}{c}3000 \mathrm{~m} \\
\text { day } 4\end{array}$ & $\begin{array}{c}3400 \mathrm{~m} \\
\text { day } 5\end{array}$ & $\begin{array}{c}4100 \mathrm{~m} \\
\text { day } 9\end{array}$ & $\begin{array}{c}10 \mathrm{~m} \\
\text { postclimb }\end{array}$ \\
\hline \multicolumn{7}{|l|}{$\mathrm{FVC}(\mathrm{L})$} \\
\hline Ultraendurance athletes & $5.34,3.47$ & $4.39,3.73$ & $5.60,3.77$ & $4.25,5.31$ & $3.64,3.90$ & $4.40,3.42$ \\
\hline Nonathletes & $4.83,3.97$ & $4.74,3.64$ & $4.78,3.80$ & $5.19,4.34$ & $4.37,3.95$ & $5.59,4.39$ \\
\hline \multicolumn{7}{|l|}{$\mathrm{FEV}_{1.0}(\mathrm{~L})$} \\
\hline Ultraendurance athletes & $4.12,3.00$ & $3.36,3.12$ & $4.2,3.16$ & $3.32,4.44$ & $3.04,3.36$ & $3.56,3.14$ \\
\hline Nonathletes & $4.24,4.72$ & $4.16,3.40$ & $4.32,3.56$ & $4.64,3.88$ & $3.96,3.48$ & $4.60,3.74$ \\
\hline \multicolumn{7}{|l|}{$\mathrm{FEV}_{1.0} / \mathrm{FVC}(\%)$} \\
\hline Ultraendurance athletes & $77.2,86.4$ & $76.5,83.6$ & $75.0,83.9$ & $78.2,83.6$ & $83.3,85.8$ & $80.9,88.9$ \\
\hline Nonathletes & $87.8,93.8$ & $87.8,93.3$ & $90.3,93.8$ & $89.5,89.4$ & $90.0,92.3$ & $82.3,87.5$ \\
\hline \multicolumn{7}{|l|}{$\operatorname{PEF}\left(\mathrm{L} \cdot \mathrm{s}^{-1}\right)$} \\
\hline Ultraendurance athletes & $13.2,8.90$ & $8.98,9.00$ & $14.4,13.2$ & $9.22,10.6$ & $9.13,8.20$ & $8.81,7.80$ \\
\hline Nonathletes & $8.83,9.06$ & $8.93,8.58$ & $9.10,8.41$ & $10.4,8.94$ & $9.16,9.45$ & $10.1,8.18$ \\
\hline
\end{tabular}

*All measures recorded between 9:00 AM and noon. Individual data are presented (male, female) in each category. FVC indicates forced vital capacity; $\mathrm{FEV}_{1.0}$, forced expiratory volume in 1 second; PEF, peak expiratory flow.

indicated AMS scores greater than baseline scores (Table 1) for most days at altitude (Figure 1). Ultraendurance athletes reported lower symptom scores than did nonathletes during the first 4 days of the climb. For altitudes higher than $3000 \mathrm{~m}$, nonathletes recorded symptoms at a lower magnitude (Figure 1). Lung "crackles" were reported in the male ultraendurance athlete at $3000 \mathrm{~m}$.

All baseline pulmonary function values (Table 1) were well above the lower limit for each measure. ${ }^{8}$ The aerobic fitness of the nonathletes was on the order of 20 $\mathrm{mL} \cdot \mathrm{min}^{-1} \cdot \mathrm{kg}^{-1}$ less than the ultraendurance athletes. These nonathletes were not unfit individuals $\left(\dot{\mathrm{V}}_{2} \max \approx\right.$ $50 \mathrm{~mL} \cdot \mathrm{min}^{-1} \cdot \mathrm{kg}^{-1}$ ); however, a minimum, relatively high aerobic fitness is required to attempt to summit Denali. The pulmonary function device was tested with the 3-L precision syringe before and after the expedition and did not lose calibration during the climb.

Both nonathletes had reduced FVC upon arrival on Denali that remained until day 5 at $3400 \mathrm{~m}$. The male ultraendurance athlete had a decrease in FVC, which occurred on day 9; on all other days both ultraendurance athletes had elevated or unchanged FVC. Postclimb measurements were the same as baseline. A trend was toward slightly higher $\mathrm{FEV}_{1.0}$ in ultraendurance athletes and a slightly lower $\mathrm{FEV}_{1.0}$ in nonathletes up until 3400 m (Table 2).

The ultraendurance athletes had either no change or a decrease in $\mathrm{FEV}_{1.0} / \mathrm{FVC}$ for the duration of the climb. Nonathletes recorded mean values higher than baseline for each altitude. The greatest variation between groups was observed at $2400 \mathrm{~m}$ and $3000 \mathrm{~m}$ (Table 2).
An increase in PEF at $3000 \mathrm{~m}$ occurred in the ultraendurance athletes and returned to baseline by $4100 \mathrm{~m}$ (Table 2). The male nonathlete had a reduction in PEF throughout the climb; however, the lowest value recorded was on day 1 at $2200 \mathrm{~m}$ and increased to a peak climb value on day 5 at $3400 \mathrm{~m}$. The female nonathlete had elevated PEF on all days with a peak value recorded on day 9.

The resting HR of the ultraendurance athletes showed an immediate increase upon arrival at $2200 \mathrm{~m}$ and did not increase further until $3400 \mathrm{~m}$ (Figure 2). A slight decrease in HR occurred at $4300 \mathrm{~m}$. The nonathletes had no immediate increase in HR upon arrival; however, HR increased from $2200 \mathrm{~m}$ to $3000 \mathrm{~m}$ and remained constant to $4300 \mathrm{~m}$ (Figure 2). Data for $\mathrm{SaO}_{2}$ were unavailable because of battery failure on day 10 and problems with data acquisition before day 4. Oxygen saturation values were similar between both groups with a decline from $98 \%$ to $85 \%$ from baseline to $4100 \mathrm{~m}$ (Figure 2).

\section{Discussion}

Obvious caution must be taken when interpreting the results from a small group of diverse individuals. Both groups consisted of 1 male and 1 female subject with a mean group difference in age and weight of 10 years and $14 \mathrm{~kg}$. The groups traveled and worked together as a team, sharing the work loads and maintaining the same ascent schedule. Apart from the first day when the subjects increased their altitude by $2200 \mathrm{~m}$, changes in altitude were limited to $500 \mathrm{~m}$ or less with extra days 


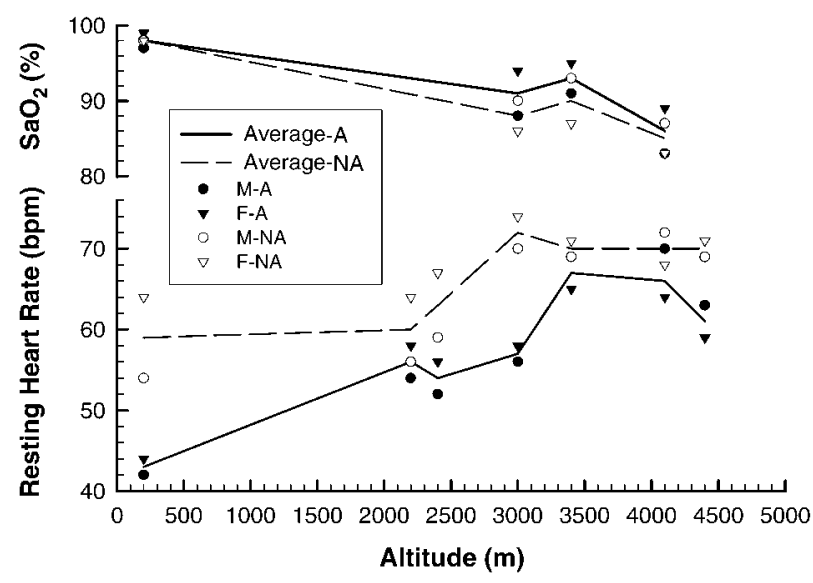

Figure 2. Top: Individual (symbols) percent arterial oxygen saturation and average ultraendurance athlete (average A) and average nonathlete (average NA) values (lines) with altitude. Bottom: Individual (symbols) resting heart rate and average ultraendurance athlete (average A) and average nonathlete (average NA) values (lines) with altitude.

spent at $3500 \mathrm{~m}$ and $4100 \mathrm{~m}$ before arriving at Basin Camp on day 10. All physiological and AMS measurements were made with the same instruments at similar times on each of the subjects. Although these instruments may have been affected by altitude, the calibration of the pulmonary function device was found to be unaffected upon return. Given these cautions and limitations, a general discussion is presented with interpretations of the data.

The influence of physical condition on the development of AMS is unclear. A recent study has linked obesity with development of AMS, which may be related to greater nighttime desaturation with altitude exposure. ${ }^{9}$ Some studies suggest incidence may increase in individuals with greater baseline aerobic fitness, whereas other studies report aerobic fitness increases a person's tolerance to altitude symptoms. ${ }^{1,2}$ Both these statements may be true because AMS symptom reports for the ultraendurance athletes were insignificant up to $3000 \mathrm{~m}$, but upon ascent to higher altitudes this group experienced symptoms of moderate severity (Figure 2). This trend was reversed in nonathletes. The low symptom scores reported by the ultraendurance athletes reflect this group's ability to function without effect at lower altitudes. Above $3000 \mathrm{~m}$, the data suggest that a highly trained athlete is penalized more severely at higher altitudes than is an untrained individual. Although the underlying mechanisms that may explain this situation are unclear, we suggest that this may be in part because of an ultraendurance athlete's ability to utilize oxygen more efficiently at a given work load, leading to less metabolic and ventilatory stress at these altitudes. Whereas the nonathletes adapted to the increase in altitude from sea level to $3000 \mathrm{~m}$ and above, this may not have occurred in the ultraendurance athletes. The metabolic and ventilatory effects of altitude became apparent after $3000 \mathrm{~m}$ when their oxygen uptake advantage was no longer present.

A decrease in $\mathrm{FEV}_{1.0} / \mathrm{FVC}$ was observed in the ultraendurance athletes between $2200 \mathrm{~m}$ and $3000 \mathrm{~m}$ (days $1-5)$. This confirms findings of Jaeger et al, ${ }^{10}$ who studied pulmonary function on immediate arrival at altitude. Because the athletes in this study were highly trained, it is unlikely that other factors such as pulmonary compliance, lung elastic recoil, or muscle fatigue could have been implicated. Because the subjects selected were highly motivated and cooperative, it is equally unlikely that poor effort could have contributed to the decline in $\mathrm{FEV}_{1.0} / \mathrm{FVC}$. The gradual increase observed in the ultraendurance athletes at $3400 \mathrm{~m}$ and above may be explained by other mechanisms. For example, mild hypoxia at lower altitude may have imposed a lower bronchomotor tone, resulting in the decline between $2200 \mathrm{~m}$ and $3000 \mathrm{~m}$. This effect might have decreased at higher altitudes because of increased pulmonary arterial pressure. Alternatively, respiratory responses to hypoxia at increasing altitude may not follow an exponential pattern and may show a diverse degree of variability. In the case of the male ultraendurance athlete, pulmonary edema may have been a contributing factor because mild crackles were diagnosed upon arrival at $3400 \mathrm{~m}$. The decrease in PEF suggests increased resistance in the smaller airways and also may be related to the peripheral effects of mild edema.

This study indicated that the highly aerobically fit individual may be more susceptible to delayed and more prolonged onset of AMS at a higher altitude than would be the moderately fit individual. The pulmonary data also suggest that the respiratory response of the 2 pairs of climbers during the ascent to $4300 \mathrm{~m}$ was dissimilar.

\section{Acknowledgments}

We wish to acknowledge the contribution of the climbers who collected and recorded the data in what were sometimes extremely harsh conditions. We would also like to acknowledge Stephen Braham, who helped prepare the gear and the team for the data collection, and Julia Low Ah Kee, who assisted in data analysis. The spirometer and pulse oximeter used in this study were supplied by the manufacturer (Jaeger Toennies $\mathrm{GmbH}$ ), who had no involvement in any other aspect of the study. This work was supported by funds obtained from Simon Fraser University. 


\section{References}

1. Hansen JE, Harris CW, Evans WO. Influence of elevation of origin, rate of ascent and a physical conditioning program on symptoms of acute mountain sickness. Mil Med. 1967; 132:585-592.

2. Hackett PH, Roach RC. High altitude medicine. In: Auerbach PA, ed. Wilderness Medicine. 4th ed. St Louis, MO: Mosby; 2001:1-43.

3. Fulco CS, Rock PB, Cymerman A. Maximal and submaximal exercise performance at altitude. Aviat Space Environ Med. 1998;69:793-801.

4. Eckhardt KU, Boutellier U, Kurtz A, Schopen M, Koller $\mathrm{E}$, Bauer C. Rate of erythopoeitin formation in humans in response to acute hypobaric hypoxia. J Appl Physiol. 1989;66:1785-1788.

5. Gore CJ, Hahn AG, Scroop GC, et al. Increased arterial desaturation in trained cyclists during maximal exercise at 580 m altitude. J Appl Physiol. 1996;80:2204-2210.
6. Howald H, Hoppeler H. Performing at extreme altitude: muscle cellular and subcellular adaptations. Eur J Appl Physiol. 2003;90:360-364.

7. Roach RC, Bartsch P, Hackett PH, Oelz O. The Lake Louise AMS Scoring Consensus Committee. The Lake Louise acute mountain sickness scoring system. In: Sutton JR, Coates G, Huston CS, eds. Hypoxia and Molecular Medicine. Burlington, VT: Queen City Printers; 1993:272-274.

8. Hankinson JL, Odencrantz JR, Fedan KB. Spirometric reference values from a sample of the general U.S. population. Am J Respir Crit Care Med. 1999;159:179-187.

9. Ge R-L, Chase PJ, Witkowski S, et al. Obesity: associations with acute mountain sickness. Ann Intern Med. 2003; 139:253-258.

10. Jaeger JJ, Sylvester JT, Cymerman A, Barberich JJ, Denniston JC, Maher JT. Evidence for increased intrathoracic fluid volume in man at high altitude. J Appl Physiol. 1979; 47:670-676. 